\title{
A Study of Climate Variability in Papua New Guinea
}

\author{
F. B. Pereira, 0. Renagi, J. J. Panakal, G. Anduwan \\ Department of Applied Physics, PNG University of Technology, Lae, Papua New Guinea \\ Email: felix.pereira@pnguot.ac.pg
}

How to cite this paper: Pereira, F. B., Renagi, O., Panakal, J. J., \& Anduwan, G. (2019). A Study of Climate Variability in Papua New Guinea. Journal of Geoscience and Environment Protection, 7, 45-52. https://doi.org/10.4236/gep.2019.75005

Received: March 31, 2019

Accepted: May 14, 2019

Published: May 17, 2019

\begin{abstract}
This Papua New Guinea is nearly tropical and we get rain in almost all seasons. But over the past few decades, it was observed that climate is changing considerably. Changes in solar influx, frequent volcanic eruptions and greenhouse gas emissions aggravate this effect. In this scenario, climate variability in Papua New Guinea has been studied using atmospheric parameters like atmospheric temperature and rainfall published by Bureau of Meteorology, Australia for the period 1996-2018. In order to improve the forecast of climate variability, the data has been analyzed using wavelet methods. An increasing trend of atmospheric temperature and rainfall are observed with a yearly periodicity except 2007-2009. The night-time atmospheric temperature showed quasi-periodic variations of two-to-four years. These variations will be discussed in terms of the SOI variations, volcanic eruptions and increase in greenhouse gas emissions.
\end{abstract}

\section{Keywords}

Climate, Atmospheric Temperature, Rainfall, Greenhouse Gas

\section{Introduction}

This climate of Papua New Guinea is equatorial climate, but along the south coast the climate is tropical. The climate is influenced by the north-west monsoon from December to April and south-east monsoon from May to October. Papua New Guinea is affected by tropical cyclones which occur from November to March and the part of the country that is affected is south central. For the past few decades, climate was changing drastically, the atmospheric temperature is observed to be increasing and the rise in temperature will cause frequent heat waves and frequent cyclones.

The atmospheric temperature and pressure have cyclical variations in a year 
but in many years, change from normal variation from the normal due to events such as volcanic eruptions, atmospheric pollution and so on. El Nino Southern Oscillation (ENSO) variation is a climatic driver of long-term variation in atmospheric temperatures. There are studies that show that ENSO variations affect climatic conditions (Yang et al., 2018). Atmospheric temperature in the northern hemisphere is affected by ENSO variation. This reveals that there is a tropical forcing on variability of polar climate (Abdillah et al., 2018). During El Nino, rainy season is dryer and warmer than normal and monsoon arrives late whereas during La Nina, more rain in the rainy season. Strong El Nino events make atmospheric conditions hotter. After a strong El Nino warming, there is often a cooling of the atmosphere in the subsequent years (Patrik, 2018).

Southern Oscillation Index (SOI) is a measure of the fluctuations in air pressure occurring between western and eastern Pacific during El Nino and La Nina events. SOI varies with changes in ocean temperatures across the eastern tropical Pacific. Negative SOI values coincide with El Nino events and positive SOI values coincide with La Nina events. ENSO events are associated with higher temperatures than non-ENSO events, with a negative correlation in subsequent years which are therefore cooler (Harger, 1995). The relation between SOI variation and atmospheric temperature of Papua New Guinea has not been studied so far. In this paper, we studied separately the variation of day time and night time temperatures and SOI variations using wavelet methods. We also analyzed the effect of atmospheric pollution on atmospheric temperature and rainfall.

\section{Data Analysis}

\subsection{Long-Term Variation of Atmospheric Temperature}

The data used in this study was the published data by Bureau of Meteorology, Australian Government (http://www.bom.gov.au/PacificIslands/png). An epoch analysis of atmospheric temperature data from 1950-2018 reveals that the average temperature of Papua New Guinea varies in a year with maximum in January and minimum in July. December to May is considered as the dry season and June to November as the wet season. The data is divided into two, one in dry season and the other in wet season. For atmospheric temperature variation study, we calculated the monthly average values during the dry season and wet season for the period from 1994-2017. An increase in trend of atmospheric temperature is observed in dry season for the period from 1994-2017. A slope of 0.022 is observed which means that an increase of 0.46 degree Celsius is observed in 21 years. No noticeable increase in temperature is observed in wet season (Figure 1).

\subsection{Wavelet Analysis of Atmospheric Temperature}

To study the temperature variation in detail, we selected the maximum temperature during day time and minimum temperature during night time for the period 1994-2017. The monthly average values are calculated and wavelet transform 


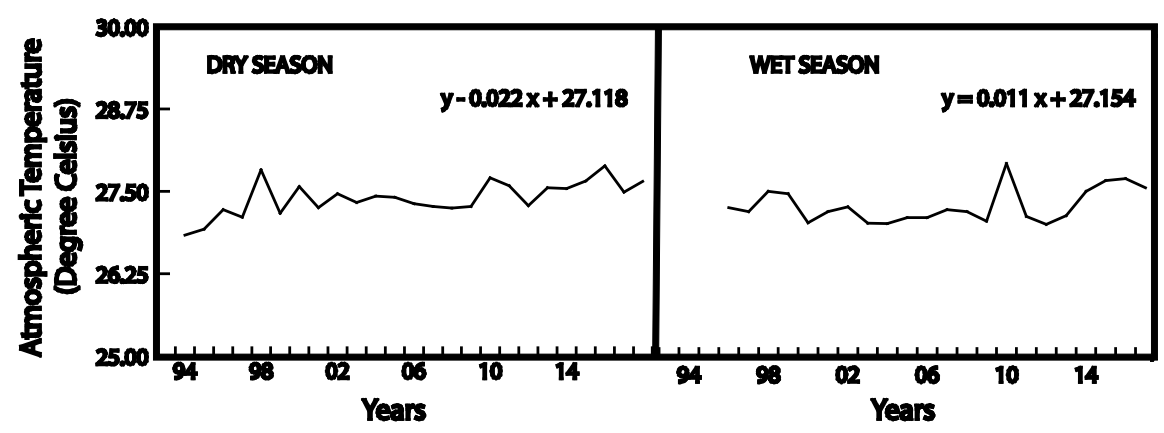

Figure 1. Variation of atmospheric temperature during Dry season (Left) and Wet season (Right) for the period 1994-2017.

is performed to study the periodicity of variation.

Wavelet analysis is used to study the variation of data which are nonperiodic. Unlike Fourier analysis which uses trigonometric polynomials, wavelet analysis generates a function called "Mother wavelet" which includes translations and dilations. Wavelet analysis is a powerful tool to find out quasi-periodic variations of a parameter by decomposing a non-linear time series into a time-frequency space (Torrence \& Compo, 1998).

The mother Morlet wavelet is defined as a complex sine wave with a Gaussian envelop and is given by

$$
g(t)=e^{\left(i \omega_{0} t-\frac{t^{2}}{2}\right)}
$$

To analyze a signal $y(t)$, we sample the wavelet transform on a grid in the time scale from $\mathrm{b}$ to $\mathrm{a}$. By setting $\mathrm{a}=\mathrm{j}$ and $\mathrm{b}=\mathrm{k}$, the wavelet coefficients $\Omega_{\mathrm{j}, \mathrm{k}}$ are calculated.

$$
\Omega_{\mathrm{j}, \mathrm{k}}=j^{-\frac{1}{2}} \int_{-\infty}^{+\infty} y(t) g^{*} \frac{(t-k)}{j} d t
$$

The wavelet coefficients $\Omega_{\mathrm{j}, \mathrm{k}}$ were calculated by performing wavelet analysis on monthly average temperature, day time maximum temperature and night time minimum temperature for the period from 1996-2018. Figures 2-4 depict the time series and wavelet power spectrum of these parameters for the period of study. The statistically significant periodicity is represented by the red colour with black outline. A wavelet analysis is also performed with SOI data. The data used for this study is taken from https://www.giss.nasa.gov/. Figure 5 shows the time series and its wavelet power spectrum.

\subsection{Variation of Rainfall and Atmospheric Carbon Dioxide}

Yearly average rainfall in Papua New Guinea is calculated from rainfall data for the period 1996-2012. An increasing trend of rainfall is observed during this period (Figure 6). The Carbon content of the atmosphere data published by Carbon Dioxide Information Centre, Oak Ridge National Laboratory is used for estimating the pollution. Per capita emission rate expressed in tons of Carbon 


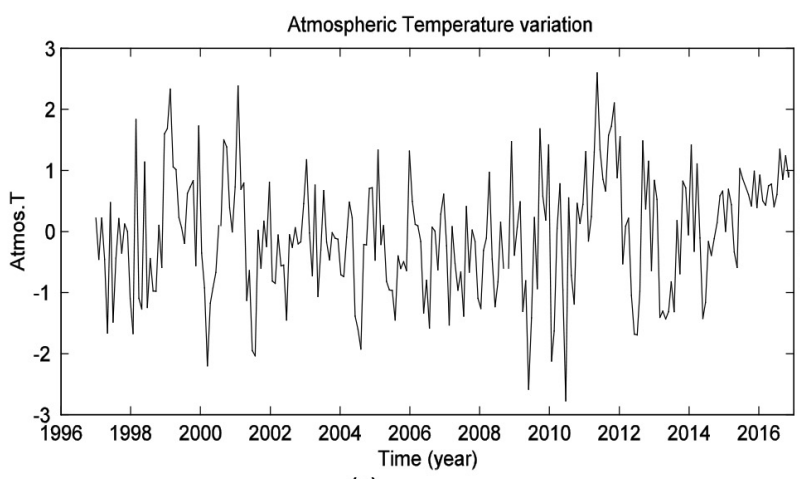

(a)

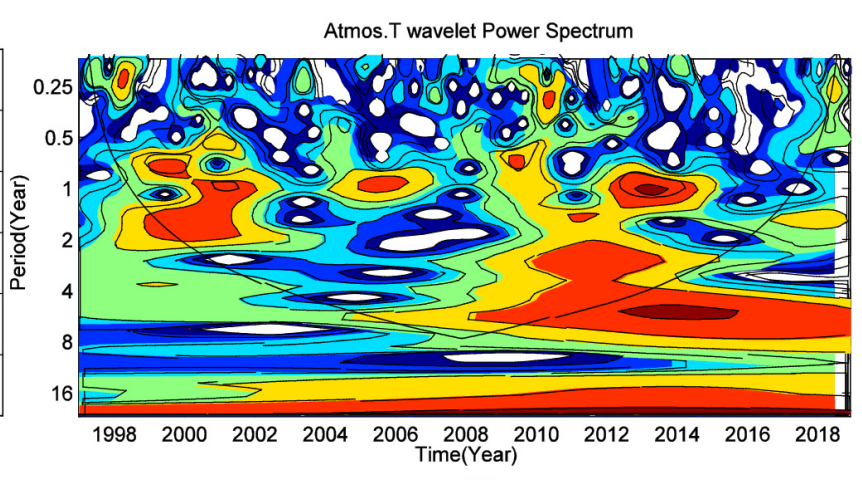

(b)

Figure 2. (a) Monthly average atmospheric temperature from 1996-2018; (b) The wavelet power spectrum of monthly average atmospheric temperature.

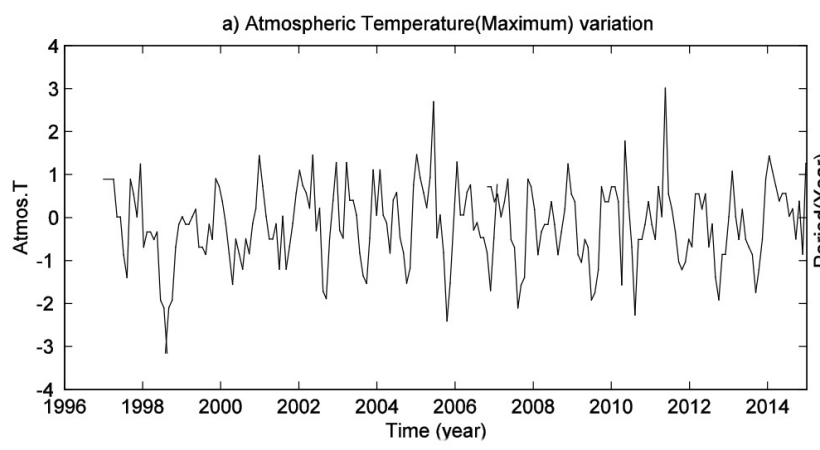

(a)

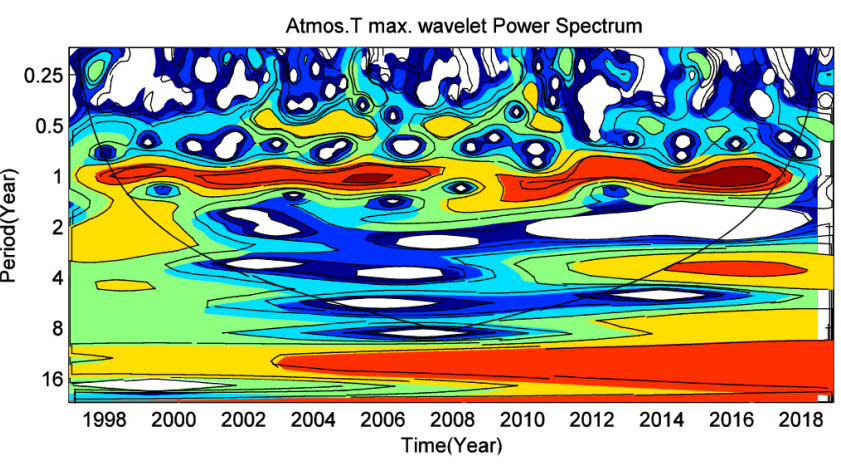

(b)

Figure 3. (a) Monthly average variation of day time maximum temperature; (b) The wavelet power spectrum of monthly average maximum temperature.

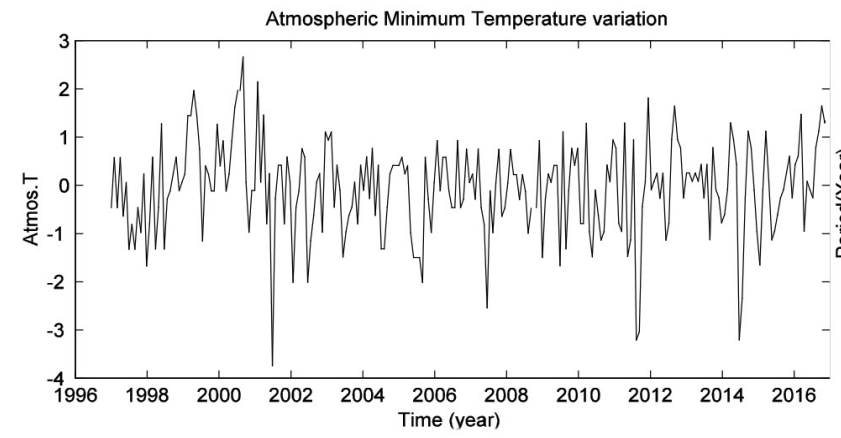

(a)

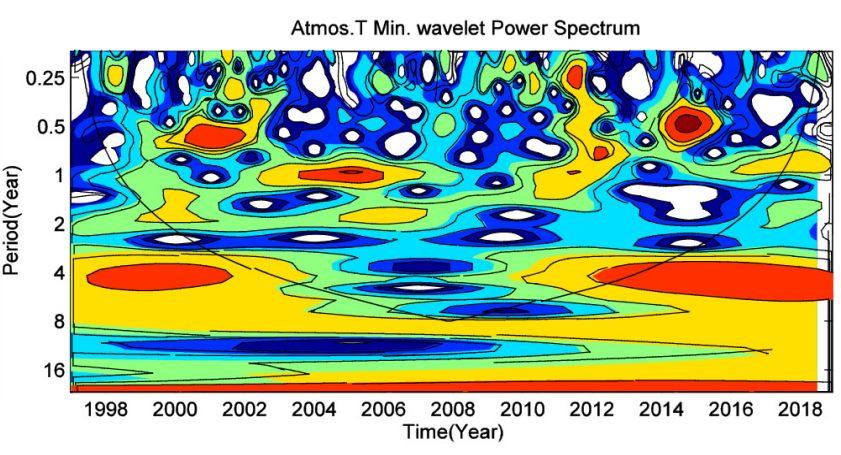

(b)

Figure 4. (a) Monthly average variation of night time minimum atmospheric temperature; (b) The wavelet power spectrum of monthly average minimum temperature.

increases from 0.12 in 1996, reaches a maximum of 0.2 tons in 2006 and decreases to 0.1 ton in 2008 (Figure 7).

\section{Results}

1) Yearly average atmospheric temperature and rainfall show an increasing trend. 


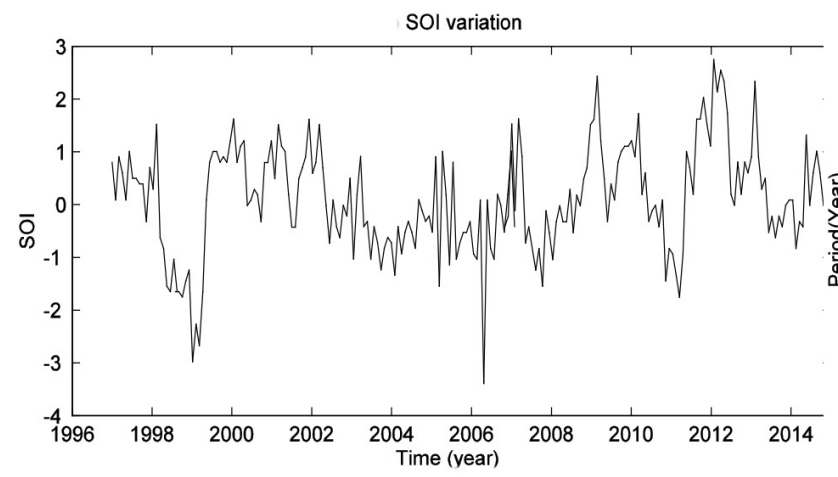

(a)

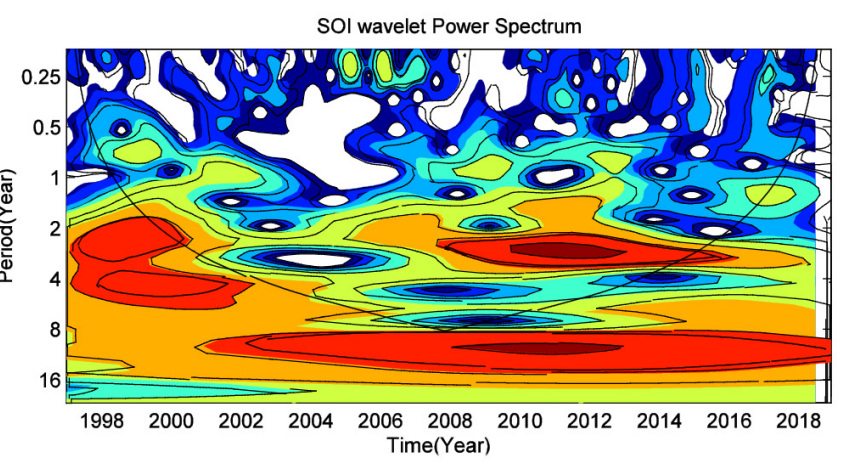

(b)

Figure 5. (a) Monthly SOI variation from 1996-2016; (b) The wavelet power spectrum of SOI variation from 1996-2016.

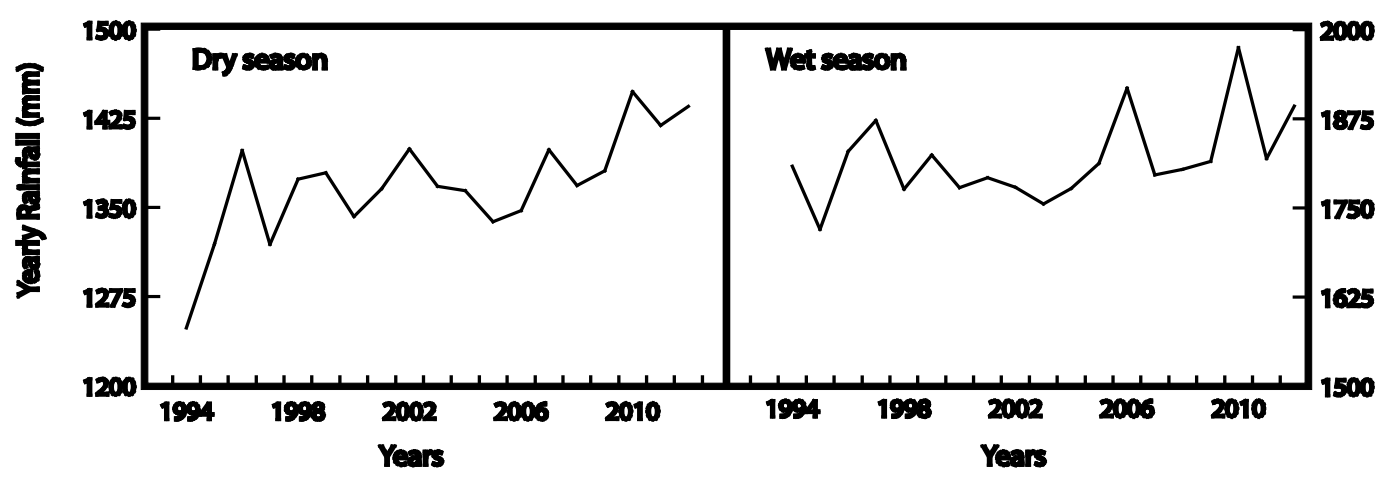

Figure 6. Variation of yearly rainfall for the period 1996-2012 during dry season and wet season.

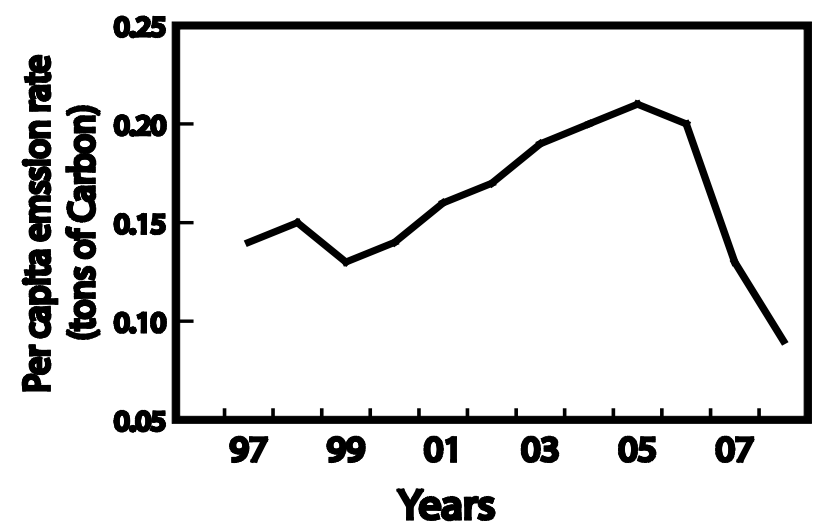

Figure 7. Variation of per capita emission rate of Carbon from 1994-2008.

2) The monthly average day time maximum temperature shows a clear one-year periodicity throughout the period of study except during 2007-2009 period.

3) The monthly average night time temperature variation shows a two-to-four year quasi-periodicity in 1998-2002 period and 2008-2018 period.

4) The per capita emission rate of Carbon in the atmosphere increases during the period 1996-2008 in Papua New Guinea. 


\section{Discussion}

The atmospheric temperature steadily increases in the dry season (Figure 1). The rainfall also shows an increasing trend during the dry season as well as in the wet season (Figure 6). The Carbon content in the atmosphere (Figure 7) increases during this period. This reveals that pollution plays a major role in increasing the atmospheric temperature and rainfall. Even though the Carbon Dioxide in the atmosphere is reduced in 2008, it will take many years to respond to the atmosphere. A decrease in long-term atmospheric temperature is expected in the coming years. This is because of the decrease in sunspot numbers during the coming sunspot maximum years. A Maunder minimum type of sunspot activity is predicted which is expected to reach a minimum value in 2070 (Meehl et al., 2013). During the Maunder minimum period which extended from 1650 to 1700, there were no sunspots (Eddy, 1976). In this period, the total solar irradiance decreases and contributed cooling in many parts of the Earth. A similar situation may arise in the coming years also. Another important parameter that controls the atmospheric temperature is aerosols. Aerosols in the atmosphere partially block sunlight by absorbing as well as reflecting it. This leads to surface dimming. The aerosols also nucleate more cloud droplets, which makes the clouds reflect more solar radiation back into space (Ramanathan \& Feng, 2009).

There is no systematic periodic variation for the monthly averaged atmospheric temperature. Quasi-periodic variations of one year and two-to-four years were observed in certain periods (Figure 2). But when we analyze wavelet spectrum for the monthly average day time maximum temperature, we could observe a clear one-year periodicity (Figure 3). Twelve-month oscillations were observed associated with solar UV absorption by ozone that dominates the seasonal variations of temperature throughout the stratosphere and lower mesosphere from 10 to $60 \mathrm{~km}$ (Pan \& Gardiner, 2003). A discontinuity is observed during 2007-2009 period. This might be due to a major volcanic eruption in New Britain Islands in late 2006. A large quantity of Sulphur Dioxide is thrown out continuously for three years into the atmosphere. It is the largest explosive eruption in Tavurvur since 1994 (McKee et al., 2011). The Sulphur Dioxide that reaches the stratosphere spreads across the globe thus reduces the temperature. The temperature in Papua New Guinea has reduced to about 0.5 degree Celsius during this period and the rainfall has increased during this period.

The wavelet power spectrum of the average minimum temperature of the atmosphere from 1996 to 2017 shows a quasi-periodicity of two-to-four years during 1996-2006 period, 2008-2012 period and 2013-2016 periods (Figure 4). A more or less similar two-to-four-year periodicity is observed in the SOI variations also (Figure 5). This reveals that the night time temperature variation is controlled by the ocean temperature. El Nino events cause variations in global average surface temperature. It is the internal dynamics of the coupled ocean-atmosphere system that determine the onset and termination of El Nino. The system oscillates between warmer period (El Nino) and neutral conditions 
in two-to-four years (Kane, 2009).

\section{Conclusion}

Climate change has had devastating effects on populations and will continue if greenhouse gas emission goes unchecked. Papua New Guinea has also been seriously affected by this phenomenon. The atmospheric temperature of Papua New Guinea is increasing day by day. This in turn increases rainfall. But this will be controlled in the near future by the reduction in solar irradiance due to a future Maunder minimum type of sunspot cycle and increase in aerosol content in the atmosphere which decreases the atmospheric temperature. The day time maximum temperature shows a periodicity of twelve months but this will be disturbed by events such as volcanic eruptions. The night time minimum temperature variations are controlled by SOI variations which has a periodicity of two to four years. In many years this periodicity is lost due to changes in the ocean currents.

\section{Acknowledgements}

We would like to thank Bureau of Meteorology, Australia, GISS, NASA and Oak Ridge National Laboratory for maintaining the data which is used in the present study.

\section{Conflicts of Interest}

The authors declare no conflicts of interest regarding the publication of this paper.

\section{References}

Abdillah, M. R., Kanno, Y., \& Iwasaki, T. (2018). Strong Linkage of El Nino Southern Oscillation to the Polar Cold Air Mass in the Northern Hemisphere. Geophysical Research Letters, 45, 5643-5652. https://doi.org/10.1029/2018GL077612

Eddy, J. A. (1976). The Maunder Minimum. Science, 192, 1189-1202. https://doi.org/10.1126/science.192.4245.1189

Harger, J. R. E. (1995). Air-Temperature Variations and ENSO Effects in Indonesia, Philippines and El Salvador ENSO Patterns and Changes from 1866-1993. Atmospheric Environment, 29, 1919-1942. https://doi.org/10.1016/1352-2310(95)00017-S

Kane, R. P. (2009). Periodicities, ENSO Effects and Trends of Some South African Rainfall Series: An Update. South African Journal of Science, 105, 5-6. https://doi.org/10.4102/sajs.v105i5/6.90

McKee, C. O., Neall, V. E., \& Torrence, R. (2011). A Remarkable Pulse of Large Scale Volcanism on New Britain Island, Papua New Guinea. Bulletin of Volcanology, 73, 27-37. https://doi.org/10.1007/s00445-010-0401-8

Meehl, G. A. et al. (2013). Could a Future “Grand Solar Minimum” Like Maunder Minimum Stop Global Warming? Geophysical Research Letters, 40, 1789-1793. https://doi.org/10.1002/grl.50361

Pan, W., \& Gardiner, C. S. (2003). Seasonal Variations of the Atmospheric Temperature Structure at South Pole. Journal of Geophysical Research: Atmospheres, 108, 4564. 
https://doi.org/10.1029/2002JD003217

Patrik, J. M. (2008). Global Warming and Climate Change. In Cato Handbook for Policy Makers (7th ed.). Danish Meteorological Institute.

Ramanathan, V., \& Feng, Y. (2009). Air Pollution, Green House Gases and Climate Change: Global and Regional Perspective. Atmospheric Environment, 43, 37-50. https://doi.org/10.1016/j.atmosenv.2008.09.063

Torrence, C., \& Compo, G. P. (1998). A Practical Guide to Wavelet Analysis. Bulletin of the American Meteorological Society, 79, 61-78. https://doi.org/10.1175/1520-0477(1998)079<0061:APGTWA>2.0.CO;2

Yang, S. et al. (2018). El Nino Southern Oscillation and Its Impact in Changing Climate. National Science Review, 5, 840-857. https://doi.org/10.1093/nsr/nwy046 